Logic and Logical Philosophy

Volume 15 (2006), 369-379

DOI: 10.12775 /LLP.2006.021

\title{
Anna Pietryga
}

\section{TARSKI'S T-SCHEME AS AN ALLEGED BASIS OF MONTAGUE SEMANTICS}

\begin{abstract}
My point in this paper is to focus on some details of Alfred Tarski's writing that in my opinion have not been aptly represented - or aptly rejected - in Richard Montague's grammar and to agree with those who share Tarski's view that human language is something uncapturable. The paper consists of two parts, concerning 1) some attempts to formalize the non-declarative utterances, and 2) the limitations of T-scheme and of Montague grammar.
\end{abstract}

Keywords: truth, natural language, illocution, sentence structure, expression names, semantic closure.

Richard Montague's grammar is classified as belonging to the logicallinguistic stream of categorial grammars (whose history starts with the work of Kazimierz Ajdukiewicz) (cf. [4, pp. 12-13, 15]. The work of Montague is often associated with his credo "I reject the contention that an important theoretical difference exists between formal and natural languages" [10, p. 188] — or with its criticism. Somewhat less in focus is Alfred Tarski's heritage. Montague justly noticed in [10] that "the model theory of the predicate calculus is of course due to Alfred Tarski" (p. 189, in the footnote, cf. [8, p. 102], footnote). Still, there are some other basic points of Tarski's heritage that need to be noticed as well - and the devil, as usual, is in the details: Tarski's remarks show weak points of Montague grammar. Thus, Tarski may be seen not only as a professor, but also as a challenger of Montague. 


\section{1a. On two attempts to formalize the natural language utterances}

The outline of semantics which Montague presented in Universal Grammar in the section "Semantics: Theory of meaning" has been described as "startling in its simplicity" [5, p. 260]. Indeed, in the section, less than one page long, Montague presents the basic ideas of model theory for simple and complex expressions (and introduces the names for various types of synonymy, cf. [11, p. 227]). There seems little in it to be noticed beyond the basic representational function of language. The interest in non-declarative sentences is rather weak in categorial grammars even nowadays. The existence of non-declarative expressions (which need not be full explicit natural language sentences — cf. [20, $§ 19],[3$, p. 5]) was pointed out (after ages of grammarians' work) by philosophers like Wittgenstein [20] and Austin [3] in mid 20th c. (1953 and 1962, respectively.) Not to notice these expressions not to give them a fair share in a grammar meant for a natural language (like Polish or English) may be considered a drawback of that grammar. Such criticism would be shared by linguists who see the "constative/ declarative" view on language as too simple - like e.g. Noam Chomsky (the main "bad character" of Montague writings ${ }^{1}$ ) or, most probably, any other contemporary linguist. Also Tarski would most probably agree with that criticism, having suggested the number of grammatical forms available in a language as a criterion of language classification already in 1933 ([16, p. 16]) and recognizing the role of extralinguistic factors for sentence valuation in 1944 $[17$, p. 240]. T-convention has been meant for declarative sentences, but these were seen by Tarski against the rich background of everyday language expressions.

The declarative bias in truth-conditional discussion of language, as explained in the Introduction to Montague semantics [5], is partly due to its historic source "within mathematical logic, an area where illocutionary acts other than statements play no role"; the authors mention, though, extensions of the method to illocutionary acts other than statements, like questions and imperatives [5, p. 13], referring the reader to a bibliography (in ch. 9 of [5]). The Introduction has been published in 1981, about 25 years after the publi-

\footnotetext{
${ }^{1}$ Noam Chomsky, an MIT professor in linguistics, is portrayed in sketchy remarks by Montague as one sharing his view that it is "possible to comprehend the syntax and semantics of [both natural and artificial languages] within a single natural and mathematically precise theory" but also as one whose work - and, in general, the whole MIT efforts had not fulfilled that ideal yet and offer little promise in this respect, cf. [11, p. 222-223], cf. also [10, pp. 188, 210], [12, p. 247].
} 
cation of the two seminal books: Wittgenstein's Philosophical Investigations, in which various linguistic games had been distinguished (the set of which is changing all the time) and Austin's work on How to do things with words, in which the author recognized the performative function of language (and laid foundations for the later - and somewhat paler - theory of illocution).

In 1985 John Searle and Daniel Vanderveken tried to fill the gap between philosophy of language and philosophical logic, publishing "Foundations of illocutionary logic". In the book the authors discussed five types of English illocutionary verbs, labelled as five illocutionary points. The list includes the following types which could be found joined in particular utterances: assertives (used to say how things are), commissives (to commit oneself to do something), directives (to make somebody do something), expressives (to express one's feelings and attitudes) and declaratives (to cause changes in the world through one's utterances) (cf. [15, p. 52]). The latter group corresponds roughly to Austin's performatives (cf. [3], [15, p. 61], [14, p. 160]) ${ }^{2}$. Searle and Vanderveken list 21 verbs in that group and give each a short analysis (pp. 205-211) ${ }^{3}$

Searle and Vanderveken hoped to generate formally the set of all illocutionary forces recursively from the primitive ones mentioned above, trying to lay bare the logical structure beneath the surface vocabulary, and presented a corresponding logic ([15], p. 49 and pp. 106-157).

\section{1b. Barbara Hall-Partee on the two formal theories}

In doing so, they become the object of criticism formulated by Barbara HallPartee in her "Belief-sentences and the limits of semantics" [6] (published

\footnotetext{
${ }^{2}$ It may be interesting to note why Austin abandoned his initial distinction: he did so being unable to find a satisfactory criterion of demarcation between performatives and constatives (i.e., the non-performatives), having tried various sorts of a "litmus paper", like the obligatory verb form of the first person singular or the possibility of adding the word hereby to a performative sentence, or - in semantics - the lack of a logical value. It would be perhaps interesting to check the division suggested by Searle and Vanderveken by Austin standards.

${ }^{3}$ Interestingly enough, the verb BELIEVE does not belong to any of the groups, while it does appear in the "English lexicon" of [10]. Montague gives also "confirmatory criteria for belief", which roughly reduce to taking somebody's assent to the truth of a proposition being asserted to be a sign of the corresponding belief, though Montague admitted that the criterion was not conclusive [9, pp. 138-139]. This is really surprising in a grammar aiming at so high a standard of precision. You may read it in Aristotle (Metaphysics, $\Gamma$ 3) that the speaker need not believe in what he says.
} 
in' 82 , that is - three years before their book), who criticised the conviction that it is possible to give a finite representation of human semantics, be it based on a formal or psychological approach. She criticized reductionists for trying to derive language from a limited set of semantic primitives as well as she criticised Montague for sketching a God-like semantics in which every possible semantic equivalence is known by the speaker (cf. [6, pp. 102-103, 90]).

The main problem Hall-Partee noticed in her paper concerns, as the title of her paper suggests, belief-sentences. In her opinion, Montague grammar cannot be "known" by a finite being like a human or a computer, because this would require that being's omniscience. She gives examples of pairs of sentences, containing

(1) logically equivalent clauses $P$ and $Q$, or

(2) proper names having the same intension, or

(3) natural kind names having the same intension

which in her opinion would be considered pairwise logically equivalent in Montague grammar. Montague [9] did indeed discuss a pair of sentences which differ in a [correferential] individual constant ( $p$ vs $q$ ). For the latter pair, Montague used and shortly discussed the following example:

(4) If the Morning Star = The Evening Star, then Jones believes that the Morning Star appears in the morning if and only if Jones believes that the Evening Star appears in the morning [9, p. 145].

However, Montague's systems presented in [9] do not in general recognize the reasonings of this type as valid ([9]: 144). The paper reaches no definite conclusion as to the validity of this type of reasoning, being in this respect more of a historical presentation of various opinions on that subject ${ }^{4}$.

Anyway, Montague may be criticised, in Partee's way, if not for overestimating English speakers' lexical knowledge, than as a reductionist, because of his views concerning the contexts of linguistic utterances. Tarski found it impossible to include pronouns and indexical expressions like HERE and THIS in formalized languages ([18], p. 314) while Montague postulated addition of personal pronouns as well as any points of reference that would seem useful for discourse analysis. Montague opinion was that contexts of

\footnotetext{
${ }^{4}$ The situation is different in the case of reasonings where one free individual variable is substituted for another: these seem to be accepted by Montague. But these are not the ones discussed by Partee in her [6].
} 
use need not be considered in their full complexity, as it is enough to confine one's attention to those features of the context which are relevant to the discourse in question. "Thus it will suffice to specify the set of all complexes of relevant aspects of intended possible contexts of use" [8, p. 98], cf. [8, p. 107], [9, p. 121]. The first task of the grammarian is to "determine the set of all possible contexts of use" [9, pp. 121-122], which might turn out less easy than it seemed to Montague. Contexts of use were (ab)used before in theory construction by linguistic schools, including behaviorists with their idea of the meaning of an utterance as a sum of the situation in which a given expression is uttered and the reaction of the hearer. The question remains: what are the units to be added.

Partee's arguments add up to the statement that complete semantics for human language is impossible; this negative result, however, gives us a blessed "awareness of our ignorance" setting us free from what may be a "false assumption [...] that a human language must have a finitely representable semantics" [6, p. 103]).

\section{2a. The limitations of T-scheme}

Partee does not mind to recognize the fact that there is a limit to man's abilities. Tarski was ready to admit his own. The T-convention was meant for formal languages only, as Tarski could not give a satisfactory structural definition of a sentence in natural language, (and of a true sentence in particular $)^{5}$, especially as we cannot have a definite list of actual and potential lexical items of that language ([16, p. 29], cf. [16, p. 158], [20, §93]). Anyway, despite new generations of logicians and linguist have appeared after Tarski, the structural definition of an English/ Polish sentence is still not there, though some formalists believed in the promise of proliferating formal possibilities, enhanced by the popularity of computers, and those who were more prudent were left behind unheard ([4], pp. 8-9, 243, [13], p. 6, 33) ${ }^{6}$.

\footnotetext{
${ }^{5}$ Tarski discussed a method of defining a set of true natural language sentences via structural definitions of sentential calculus tautologies, noticing it is also possible to define likewise a false statement of natural language. The method, however, seemed futile to him. Cf. [16, pp. 28-29].

${ }^{6}$ The problem of sentence definition is one of the subjects amusingly presented by Jean Aitchinson in The articulate mammal. In the book a story is given about a captain of a spacecraft (significantly named Noam) and his crew, forced on Jupiter to teach extraterrestials the secret of their human spoken language: unable to solve the problem of how to produce a correct sentence, they tried to make their oppressors believe various answers,
} 
The logical definition of a sentence as "a formula without free variables" [8, p. 102]), apparently the only definition of a sentence to be found in Montague's writings, is evidently not apt to be accepted in linguistics where we do not have a formal definition of "an English formula".

This means we cannot recognize - and suggests that Montague could not recognize either - sentences (and true sentences in particular) among the English language sequences we encounter, simply by their form, like we recognize sequences of signs as correct expressions in the language of logic (and sometimes we recognize them as tautological). It should also be noticed that the T-scheme is not sufficient to determine the truth value of a sentence, as has been explicitly pointed out and clearly explained by Alfred Tarski ([18], pp. 317-318): T-scheme helps formulate the truth conditions of a given sentence, but give no other help in establishing whether a given sentence is actually true or not. In [16] (that is, in 1933) he made a similar statement, writing about problems in defining satisfaction as a main obstacle for truth definition ([16], pp. 130-131). It is not enough to know a function from individuals to truth values - and this is how semantic value of sentences (strictly speaking - of verb phrases) is defined in Montague grammars (cf. [5], pp. 32, 8) - to predict its value for a particular sentence ${ }^{7}$. Tarski warned the reader he or she would get disappointed if he expected T-scheme to give such solutions ([18], pp. 317-318). It should be also noticed that, according to Tarski, T-scheme is not a definition of truth (cf. [17], p. 236) (though in [18] he is using this expression himself for conjunction of T-scheme applications to particular sentences, cf. p. 299).

\section{2b. The missing parts of Montague grammar}

It is only understandable that Montague, being a Tarski's doctoral student ([21], p. XVII) concentrated his categorial attention on the theory of truth,

all of which were consecutively rejected. The story reflects the development of modern linguistics, including e.g. finite state grammar.

${ }^{7}$ Categorial grammar specialists tend to ignore the fact that T-scheme does not allow to establish truth or falsity of particular sentences, be their grammar concentrated on the theory of truth or of inference [7, p. 33]. In both of these approaches the concept of truth is essential. Categorial grammar specialists would offer the method of calculating the truth value of $p$ as a function of the truth value of $q$, although the truth value of $q$ is not known, or even cannot be known, given the present state of knowledge. It may be agreed that classical logic does the same. Still, it does not say, as some categorical grammarians would (cf. [4], pp. 238-239), that the analysis of the notion of truth is beyond their field, being a subject of formal logic instead. 
and his grammar is a sort of expansion of T-scheme. (In his grammar, a sentence "snow is white" is true whenever the snow is white in a given model.) Montague declared that in his opinion the "basic goal of serious syntax and semantics" was the construction of the notion of truth under an arbitrary interpretation [10], p. 188). He evidently did not share his professor's view that, for natural language, it is not possible to define a notion of truth, or even use this notion consistently and in a logical way ([16], pp. 15, 158), for complex reasons which focus in the liar's paradox. (This view had been expressed by Tarski even before the publication of [16], namely in its early version, published in 1932.)

Tarski used the "inverted commas" formulation of the paradox, taken from Jan Łukasiewicz, cf. [16, p. 21], in which by means of a typographic convention it is established to understand " $c$ " as equivalent to the sentence $c$ is not a true sentence. This leads to a following paradoxical statement: $c$ is a true sentence iff $c$ is not a true sentence, via a general scheme for defining what it means for a sentence to be true ( $x$ is a true sentence iff $p$, where $x$ is the name of the sentence and $p$ is the sentence itself). The source of antynomy is, as Tarski notices, the fact that the typographical convention involved contains the expression "true sentence" (which no rule had forbidden to prevent the appearance of the paradox). An additional problem is caused by the fact that " $c$ " is also a name of one of the letters of the alphabet and as such cannot be always substituted for, as can be seen e.g. in the word comma. This renders the intuitively correct "truth definitions" for Polish sentences — which Tarski formulated himself in the first part of his [16] for the reader to naively accept - a sheer nonsense. Therefore, the truth definitions involving quotations "cannot be generalized in any reasonable way" [16, p. 24].

Facing the difficulties mentioned above in the attempt to define truth for natural language, Tarski suggested to try another way: the construction of a structural definition of a sentence, but he found such efforts unavoidably fruitless (p. 31). The first paragraph of [16], dealing with natural language, ends with an early version of what will develop in later Tarski's work into the definition of semantically closed languages as distinct from natural languages (cf. [17], pp. 242-243, [14], p. 159) ${ }^{8}$. The difference involves, besides the aforementioned formal syntactic rules and established lexicon of formal languages, also the presence, in natural language, of the names of that lan-

\footnotetext{
${ }^{8}$ The lack of proper understanding of semantic closure has been a source of many mistakes. Cf. [14], p. 158n.
} 
guage expressions, as well as semantic terms (like TRUE) together with the rules of their usage, all of them formulated in the language. In $\S 5$ of [16] (p. 139) Tarski writes about the long-known disrepute of semantic concepts, which evaded precise explanation of their sense and led to antinomies despite their being intuitively correct.

It seems Montague does refer to [16] in "English as a Formal Language". Nevertheless, the title of his paper leaves hardly any doubt that Montague meant to treat English as if it were a formal language (as there is, in his opinion, no theoretical difference between natural and formal languages). Montague grammar as presented in [10] consists of a lexicon and a list of syntactic rules (both to be mirrored on semantic level). Montague wrote in that paper: "it is already known how to extend the treatment rather widely in various directions" [10, p. 189]. Indeed, one could say, it is already known how to extend the set of English basic name phrases. (Particularly promising in this respect is the vocabulary of teenagers, which seems to be the quickest changing subset of natural language lexicon.) Also, Montague's lexicon given in [10] seem not to include yet semantic terms like TRUE as well as "such indexical adjectives as FORMER, such quantificational adjectives as EVERY, MOST and THREE, and adjectives of certain other exceptional varieties" [10, pp. 190-191]. It seems to me that those "exceptional" adjectives, had they been allowed to appear on the list, would facilitate the construction of the liar's paradox on Montague's terms. The "English language" of [10] hardly allows to formulate quotations. Thus, it does not share with the English that is actually being spoken what Tarski called the universal character of natural language (as opposed to formalized languages, cf. [16, p. 33], namely the possibility of speaking in it about any subject: "if anything can be sensibly spoken of, it can be spoken of in natural language" [16, p. 30]. Montague draws hasty generalizatons from what he sees in a deliberately limited language sample. The limitation might have been introduced "purely for simplicity" or "for expository purposes", ([9], p. 121, [5], p. 179), but the profit of avoiding the real problems might have been tempting for the author as well. In [10] Montague admitted that he had restricted himself to a small fragment of English "partly because there are portions of English I do not yet [!] know how to treat, but also for the sake of simplicity and the clear exposition of certain basic features" ([10], pp. 188-189; cf. [11], p. 237, where the reader is informed about the limitation without any explanation whatsoever concerning its reasons).

The change of position from logically demanding one Tarski represented to the rather relaxed position of Montague seems to me to hinge on a short 
passage in [10, p. 208]. Beginning the section on "Truth and logical truth", and referring to the last theorem of the previous section, Montague wrote: "The third part of the last theorem indicates that we may define a true sentence of our fragment in the manner suggested in Tarski [16] for mathematical languages, as one 'satisfied' by every infinite sequence (or, equivalently, by some infinite sequence)".

If we wanted to develop the grammar "in the manner suggested in Tarski [16]", we should notice that he clearly and repeatedly stated that it is possible to give precise definitions related to the term TRUE only for a language for which we know 1) its full lexicon and 2) purely formal syntactic rules which allow to discern sentences among other expressions of that language ([16], pp. 29, 158, [18], pp. 302, 313, [17], p. 240). Tarski also stressed that using the term "formal languages" he did not mean anything basically opposed to natural languages - on the contrary, only those formalized languages seemed to him really interesting which were fragments of natural languages (fragments equipped with full lexicons and precise syntactical rules) or which can be at least translated into natural languages. In [18, p. 302] Tarski wrote that for "obvious reasons" fragmentary truth definitions (resulting from an application of T-scheme) for a number of sentences can not be expanded to cover the whole of the Polish language. In the same paper Tarski admitted, though, that perhaps such general definition of a true sentence might be obtained by some totally different method (the text was published in 1969, i.e., after the publication of Chomsky's Aspects of the theory of syntax and after Montague's "Pragmatics"). Even in such case, Tarski wrote, there still exists a major problem, namely, the liar's paradox.

Thus, the practical difference between the formal and natural languages becomes, I hope, visible as Mogntague credo becomes more of an empirical issue. Tarski's challenge requires addition to "Montague English" of formal definition of a sentence, expression names and richer lexicon sample. The new sample should include semantic concepts of the type indicated above (i.e., especially the term TRUE), for which it should be possible to formulate the rules of usage in the same language. Preferably, the new language should remain semantically closed, i.e., not only have a well-defined lexicon, but also formal rules of sentence creation.

\section{References}

[1] J. Aitchison, Ssak, który mówi. Wstęp do pycholingwistyki (The articulate mammal. An introduction to psycholinguistics), Warszawa, PWN, 1976/1991. 
[2] K. Ajdukiewicz, "O spójności syntaktycznej" 1935, in: Język i poznanie, vol. I, Warszawa, PWN, 1960, pp. 222-242.

[3] J.L. Austin, How to do things with words, Oxford University Press. 1962.

[4] W. Buszkowski, Logiczne podstawy gramatyk kategorialnych AjdukiewiczaLambeka. Warszawa: PWN, 1989.

[5] D. R. Dowty, R.E. Wall, and S. Peters, Introduction to Montague Semantics, Dordrecht, D. Reidel Publishing Company, 1981.

[6] B. Hall Partee, "Belief-sentences and the limits of semantics", in: S. Peters and E. Saarinen (eds.), Processes, beliefs and questions, 1982, pp. 87-106.

[7] A. Luchowska, Modele redukcyjne w semantyce (Reduction models in semantics), Uniwersytet Opolski, Instytut Filologii Polskiej, 1995.

[8] R. Montague, "Pragmatics", in: R. H. Thomason (ed.), Formal philosophy. Selected papers of Richard Montague, New Haven, Yale University Press, 1968/1979, pp. 95-118.

[9] R. Montague, "Pragmatics and intensional logic", ibid., 1970/ 1979, pp. 119 147.

[10] R. Montague, "English as a formal language", ibid., 1970/1979, pp. 188-221.

[11] R. Montague, "Universal Grammar", ibid., 1970/1979, pp. 222-246.

[12] R. Montague, "The proper treatment of quantification in ordinary English", ibid., 1970-1973/1979, pp. 247-270.

[13] Z. Pawlak, Gramatyka $i$ matematyka (Grammar and mathematics), PZWS, Warszawa, 1965.

[14] A. Pietryga, "Two kinds of unexpected problems in writings on logic", Logic and Logical Philosophy 15 (2006), 155-162.

[15] J. Searle and D. Vanderveken, Foundations of illocutionary logic, Cambridge, CUP, 1985.

[16] A. Tarski, "Pojęcie prawdy w językach nauk dedukcyjnych" ("The concept of truth in formalized languages", in: A. Tarski, Logic, semantics, metamatemathics. Papers from 1923 to 1938, Clarendon Press, Oxford, 1956, pp. 152-278.), in: A. Tarski, Pisma logiczno-filozoficzne, vol. 1 Prawda, Warszawa, Wydawnictwo Naukowe PWN, 1933/1995, pp. 13-172.

[17] A. Tarski, "Semantyczna koncepcja prawdy i podstawy semantyki" ("The semantic conception of truth and the foundations of semantics", in: Philosophy and Phenomenological Research 4(3) (1944)), ibid., 1944/ 1995, pp. 228-282.

[18] A. Tarski, "Prawda i dowód" ("Truth and proof", in: Scientific American 220(6) (1969)), ibid., 1933/1995, pp. 293-332. 
[19] R. H. Thomason, "Introduction", in: R. H. Thomason (ed.), Formal philosophy. Selected papers of Richard Montague, New Haven, Yale University Press, 1979, pp. 1-69.

[20] L. Wittgenstein, Dociekania filozoficzne (Philosophical investigations), Warszawa, PWN, 1953/1972, (Ludwig Wittgenstein, Philosophical Investigations, Prentice Hall, 3rd edition, 1999).

[21] J. Zygmunt, "Alfred Tarski - szkic biograficzny" ("Alfred Tarski - an autobiographical sketch"), in: A. Tarski, Pisma logiczno-filozoficzne, vol. 1 Prawda, Warszawa, Wydawnictwo Naukowe PWN, 1995, pp. VII-XXIV.

\author{
Anna Pietryga \\ Instytut Filologii Polskiej \\ Uniwersytet Opolski \\ Opole, Poland \\ apap@vp.pl
}

